\title{
THE ROLE OF THE MEDIA AND COMMUNICATION TECHNOLOGY MANAGEMENT IN DEVELOPING THE MEDIA INSTITUTION (Alarabiya.Net Site as a model)
}

\author{
HARITH YAS KHUDHAIR ${ }^{1}$, ABU BAKAR ABDUL HAMID ${ }^{2}$ \\ Department of Mnagnment, Universiti Teknologi Malaysia, Johor Bahru, Malaysia \\ Harith.albayati@yahoo.com \\ Department of International Business School, Universiti Teknologi Malaysia, \\ Johor Bahru, Malaysia \\ Bakarhamid3030@yahoo.com
}

\begin{abstract}
Media institutions have a great impact on the day to day life of the public. Information conveyed by these institutions can improve the relationship of the people or, on the contrary, create misfortunes among them. Due to this reason, in the development of media institutions, proper incentives are supposed to be put into consideration in order to make them worth to the target audience. On the other hand, media play an important role in conveying political, economic and also social news that is required by the public. To avoid distortion of information, proper management of what is conveyed by these institutions need to be put in place.
\end{abstract}

Keywords: Media, Online Broadcast, Communication Technology, and Management.

1. Introduction. Management in any institution or company is of essence and significantly important to the functioning of the institution. For any activity to be undertaken efficiently, proper planning and organizing of activities is required. Management plays very important role in any business organization. Were it not for the management, business firms could not progress or achieve their goals for that matter. Therefore, for the goodness and prosperity of the business institutions, management needs to work coherently and comprehensively. In the development of media institutions, media and communications technology management have various roles that are required to practice in order to make these institutions effective in their working. Management in any institution or company is essentially significance. For any activity to be undertaken efficiently, proper planning and organizing of activities is required (Boyd, 2001). Management plays very important role in any business organization. Were it not for the management, business firms could not progress or achieve their goals for that matter. Therefore, for the prosperity of the business institutions, management needs to work coherently and comprehensively. In the development of media institutions, media and communications technology management have various roles that are required to practice in order to make these institutions effective in their working.

2. Literature Review. One of the main roles of media and communications technology management is drawing up national policies to guide the working of media institutions. Every institution has specific policies that it follows during implementation of their duties. Policies are meant to guide the business firms on how to undertake certain activities in order to avoid committing an offense or crossing the boundaries in the line of duty. They are also meant to update people on their position in the surrounding society hence avoid under or over playing the responsibilities that one is assigned (Eveland et al., 2004). The management has the mandate to draw all the policies and make sure those subjects effectively implement them to them. The applicability of 
the concepts in discussion includes the analysis of media development and the advancement of the media in this regard.

In media development, media and communications technology management has the full mandate to draw up and implement all the policies to guide member's staff in these institutions. Media is well known to have a significant impact on the living of the general public (Boyd, 2001). Information conveyed by these broadcasting companies can lead to the development of the society and, on the contrary, can lead to breaking up of ties in the society, leading to all kind of vices in the society. It is due to this reason that the management is required to draw up the policies to guide the member's staff on the kind of information to relay to the community. Media also plays an important role in the national economy. Economic information broadcasted by media can lead to diverse investments in the country that help in the projection of national economy positively (Henry, \& Springborg, 2010).

Channels of communication are essential in giving information. One should not ignore for whatsoever the kind of channel used in relaying the information. People will differ in their attitude towards various types of channels. Some people will tend to go for televisions, others gazettes and radios depending on the taste and abilities that one have. People will also vary in the understanding of information depending on the channel used. It is with this concern that the management is supposed to plan well on the type of channel to be used in relaying the information. Media and communication technology management should know the target audience when deciding on the media channels (Eveland et al., 2004). When developing a media institution, there is always a target audience that the firm is developed to serve. The audience may vary in the accessibility of the channels of communication depending on their capabilities. Those audiences in low social class may only be able to access a cheap channel of communication, for example, a radio. Therefore, the management should be able to know the class that the target audience they are in order to decide on the effective system to use. Modern systems of communication should also be used to motivate the audience when listening, reading and watching these broadcasting channels.

The other role of the management is to plan for the resources that are going to be used in developing media institution. Every business has the common resources that it uses depending on its working and the kind of investment it has engaged in. One needs to plan for the resources prior to the initiation of the whole program to avoid stoppage of development due to inadequate resources. Liquid cash and equipment are required in developing a media institution (Hafez, 2001). The currency is required in the sense that many some equipment need to be purchased and also professionals to undertake the program need to be paid. It is with this concern that the management needs to consider the available resources in order to have a good scope of the program.

The management should know the effectiveness of media channels. A number of equipment will be required in developing a media institution. The kind of equipment used is also a determinant factor in the progression of the media institution. The management, therefore, will be required to plan on which equipment will be effective and efficient in developing the media. Therefore, for effective planning of resources, the management need to consider the number of the professionals that will require undertaking the process of development and also the equipment required. The media management has a role in fostering training to the member's staff. In order to develop a media institution effectively, stakeholders in the process need to be properly trained to boost their competence.

The management has the full mandate to undertake training processes for the members who are directly or indirectly involved in the development process. There is a need for effective communication when conveying or coding information. The media personnel to affect the programs needs to be highly trained in this field for an effective communication (Boyd, 2001). They should also be able to determine their target audience and, therefore, use the language register that go hand in hand with the age and social class of their audience. The stakeholders also need to know the policies governing the working of the media institution. Hence, the management will be required to train their employees on the policies to make them conversant and know their position in the line of duty.

The media and communications technology management also has a role of editing the information before is 
published to be read by the public. Sometimes distortion of information may be experienced during recording and printing. This can lead to misunderstanding of information or misquoting which can cause negative feedbacks from members of the public. The audience may also not comprehend the information due to poor language or blatant mistakes committed (Henry, \& Springborg, 2010). The edition should also be done to eliminate information that can raise controversies among the public. It is with this concern that the management is required to edit the information before it reaches the audience.

It should also do information editing before it is disclosed to the public or target group. The information should also be edited to fit the target audience. The intention of the communication is to update the audience on the past, present and prevailing issues. The issues may not necessarily be for the general public rather particular age group or social class. For the information to be understood by the targeted group register, need to be put in place. For instance, if a certain issue is being addressed to the youths, less official language should be used. The management should, therefore, edit the information to fit the target audience to foster understanding.

The management should create an interface between the writers and readers. This is extra service that is meant to boost the working of the institution. Writers and readers interaction is essentially significance in media as both are able to learn from each other. To achieve this, the management is required to give an opportunity to the readers to comment on the writer's work. For example when launching a website, the management should make sure there is the full accessibility of information uploaded and additionally give the readers opportunity to comment on them. This will give the audience the chance to air complaints and compliments concerning the information in question. The writers will also learn from the readers and improve on their work for the development of an effective media institution.

Finally, the management has role of bringing down the cost of manufacturing information in media institutions. If not managed well, manufacturing information can incur a heavy cost to the institutions. This can lead to depletion of resources that are used to manufacturing resources due to high input. To avoid this, the management is supposed to control the cost incurred media processes by using the cheapest the ways possible. This enhances the smooth progression of media institutions since huge losses do not stick them during their work.

3. Methodology. The quantitive analysis among the media institution in order to come with dependable statistics concerning the use of communication technology in the institution. The researcher went out and collected the data from the media institutions where communication technology have been implemented and properly managed. The researcher was able to come up with data analysis of how the institution have benefited from the communication technology depending on the level of execution. Additionally, the researcher came up with the extent to which the interests of the institution have gone in planning for the communication technology in their websites.

4. Analysis. The following graph shows the importance of the communication technology depending on the extent at which the media and communication technology management have executed the project in the institution.

Table. 1 communication technology to be important in developing the institution

\begin{tabular}{|c|c|c|c|c|}
\hline Count & Average & Weights & \multirow{2}{*}{ MEAN } & \multirow{2}{*}{ STDEV } \\
\hline 164 & $82 \%$ & 5- Important & & \\
\hline 0 & $0 \%$ & $\begin{array}{l}\text { 4- Important to a large } \\
\text { extent }\end{array}$ & \multirow{4}{*}{4.49} & \multirow{4}{*}{1.10} \\
\hline 6 & $3 \%$ & 3- Important to some extent & & \\
\hline 30 & $15 \%$ & 2- Unimportant & & \\
\hline 0 & $0 \%$ & 1- Don't know & & \\
\hline
\end{tabular}




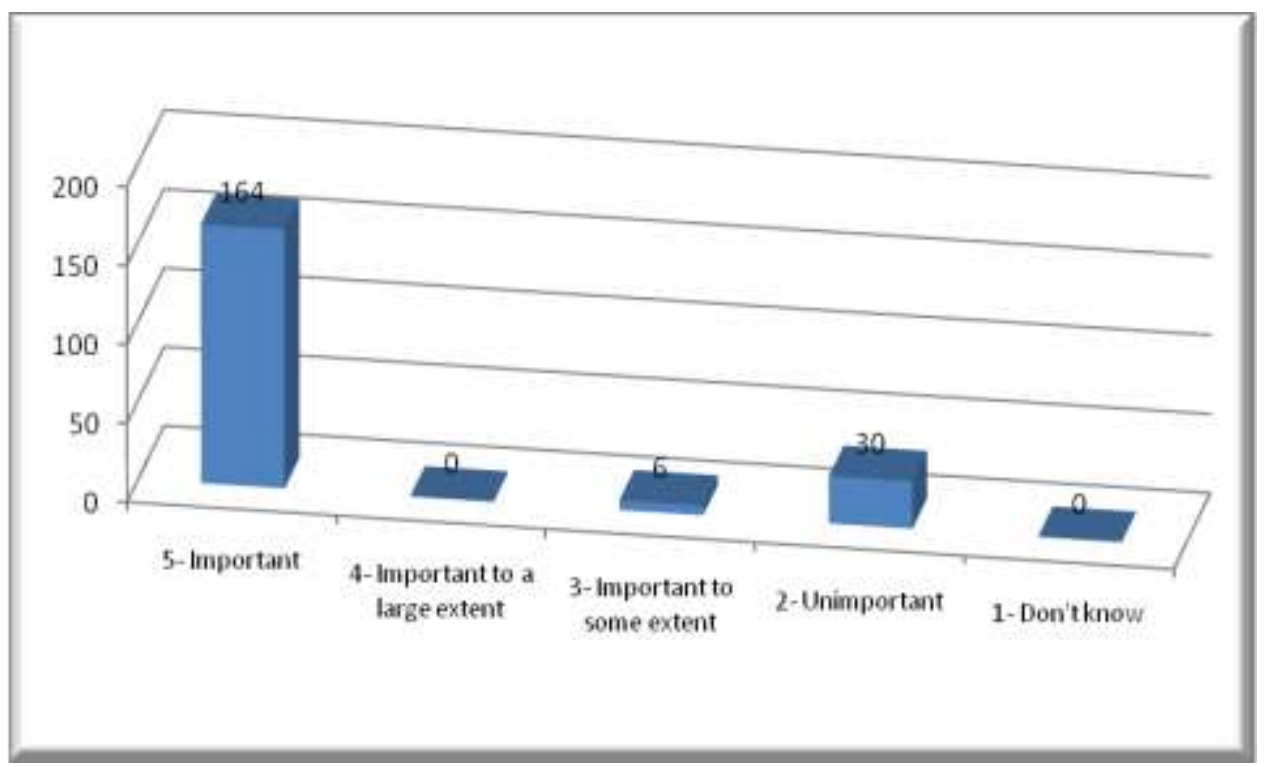

Figure.1 Communication technology to be important in developing the institution

Through the above mentioned methodology, the researcher was able to come up with the following statistics. The graph below shows the extent at which the institutions interest have gone in the planning processes in its website.

Table.2 Extent of the Institution's interest in the planning process its websites

\begin{tabular}{|c|c|c|c|c|}
\hline Count & Average & Weights & \multirow{2}{*}{ MEAN } & \multirow{2}{*}{ STDEV } \\
\hline 87 & $44 \%$ & 5- Strong interest & & \\
\hline 53 & $27 \%$ & 4- Average interest & \multirow{4}{*}{3.88} & \multirow{4}{*}{1.24} \\
\hline 13 & $7 \%$ & 3- Small interest & & \\
\hline 43 & $22 \%$ & 2- No clear interest & & \\
\hline 4 & $2 \%$ & 1- Don't know & & \\
\hline
\end{tabular}




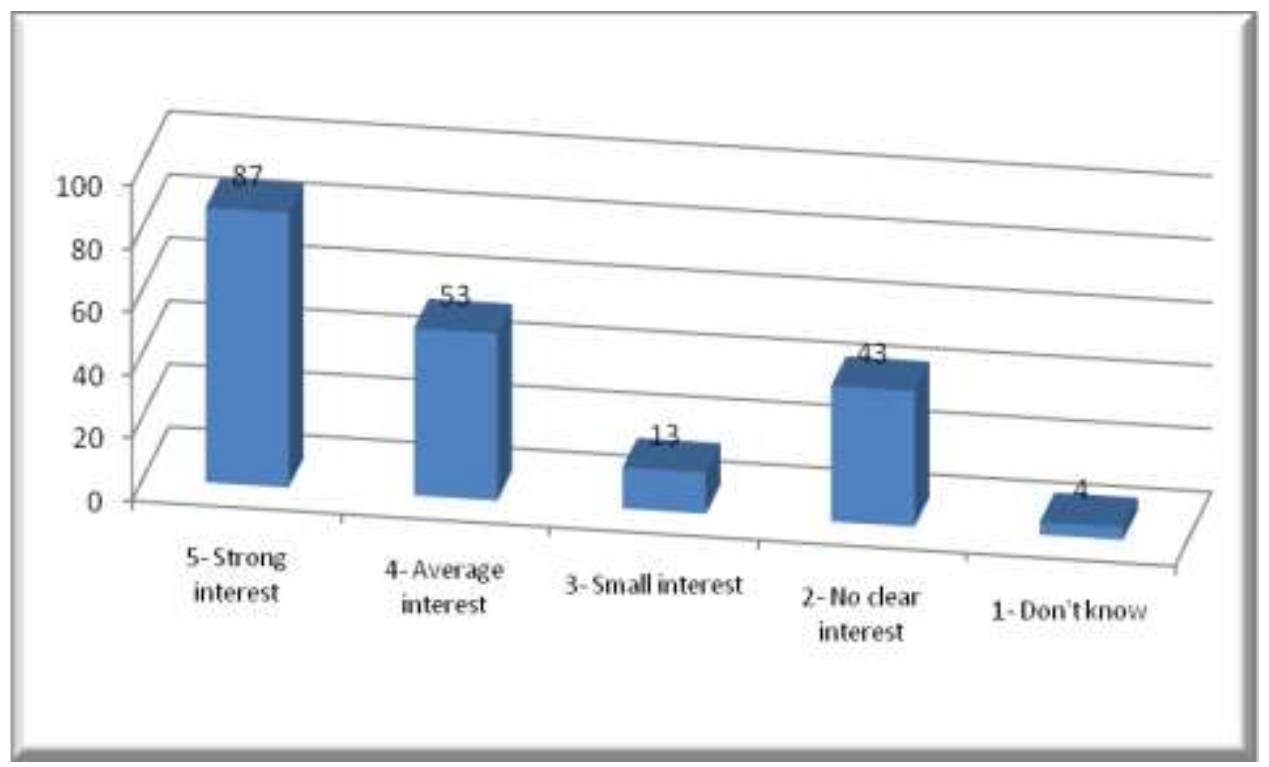

Figure.2 Extent of the Institution's interest in the planning process its websites

5. Results. The results obtained from this study is as discussed in this section mainly concerned with the various aspects of the research study upon which conclusions, and recommendations were to be made. The increasing level of importance of communication-based technology in the development of the institution of the media was assessed. Moreover, the interests that the institutions have in as far as the improvement of the performance of individuals were analyzed. Additionally, the planning role of the media institutions in relation to the development of its content is mentioned (Nour, 2005). Each role played by the management has a particular significant to these institutions. It is through management that these institutions are able to know the policies governing the media. The management enhances the effective communication of information to the target audience. Media and communication technology management manage information institution using modern communication technology. Due to increased number of media institutions, with time it has become difficult to manage all these institutions without using mechanical support from machines (Lister et al., 2003). Therefore, the management is entitled to develop a system of machines that will be able to supervise these institutions closely. The systems should be able to correct media institutions as soon as the mistake is committed to avoiding accumulation of mistakes. Training of the employees on the policies is important as one will know the rules and protocols that are supposed to be followed to avoid committing an offense. Having the same skills and trained on the same grounds, the employees will also be able to incorporate and integrate their ideas coherently. This will provide an interface between all members' staff in the media institution (Qirat, 2006).

6. Conclusion. Media and communications technology management has accountabilities in the workplace that range from the essence of the formation of management concepts to the running of these institutions. Communication technology management also has a significant role in media technology, with the consideration that advancements in technology and the applicability of each aspect is changing fast. As technology grows, media technology is supposed to move steadily with the same speed as world's technology. Management also is entitled to put in place the system of machines to monitor the working of these media institutions. This enhances proper management of staff members working in these institutions. Moreover, finally the media and communications technology management plays a role in bringing down the cost used in manufacturing information by media institutions. In this regard it can be concluded that the management is required for this matter to put in place the modern systems in these institutions for them to be able to convey information to the target audience effectively. 


\section{REFERENCES}

[1] Alexander, A. (2004) Disruptive Technology: Iraq and the Internet in Miller, D (ed.) tell Me Lies: Propaganda and media Distortion in the Attack on Iraq.Pluto Press. P132.

[2] Boyd, D. A. (2001). Saudi Arabia's international media strategy: Influence through multinational ownership. Mass media, politics, and society in the Middle East, 43-60.

[3] Eveland, W. P., Marton, K., \& Seo, M. (2004). Moving beyond "just the facts" the influence of online news on the content and structure of public affairs knowledge. Communication Research, 31(1), 82-108

[4] Gillmor, D. (2008). We the media: Grassroots journalism by the people, for the people. "O'Reilly Media, Inc.".

[5] Glossary of Graphic Design and Web Page Design Terms. Illinois .U.S.A.

[6] Henry, C. M., \& Springborg, R. (2010). Globalization and the Politics of Development in the Middle East (Vol. 1). Cambridge University Press.

[7] Ismail, Dania, (2004), the Electronic Website of Arabic Satellite Channels and Electronic Newspapers, M.A. Thesis, University of London.

[8] Lister, M. D., Giddings, J., Grant, S., \& Kelly, I. K. 2003. New Media: A Critical Introduction.

[9] Hafez, K. (Ed.). (2001). Mass media, politics, and society in the Middle East. Hampton Press (NJ).

[10] Rafi, Sameer, (2009), Scientific Research and Technology Management, Journal of technology vol. 2, Syria.

[11] Qirat, Muhammad, (2006), Management of Media Institutions in the United Arab Emirates in the 21st Century, Al0Bayan, Dubai.

[12] Nour, S. S. O. (2005). Science and Technology development indicators in the Arab Region: A comparative study of Gulf and Mediterranean Arab countries. Science and Technology, 3. 